\title{
Adding 'cherry to cake' just like integrating Project Based Learning with Conventional Teaching for Database Engineering Course
}

\author{
Ms. R.K. Dixit, Mrs. M. A. Nirgude, Dr. Mrs. P.S. Yalagi \\ ${ }^{[1]}$ Computer Science \& Engg. Dept., Walchand Institute of Technology, Solapur. \\ ${ }^{[2]}$ Information Technology Dept., Walchand Institute of Technology, Solapur. \\ ${ }^{[3]}$ Computer Science \& Engg. Dept., Walchand Institute of Technology, Solapur. \\ ${ }^{[1]}$ rashmirajivk@gmail.com \\ ${ }^{[2]}$ nirgudemanisha@gmail.com \\ [3] pratibhayalagi@gmail.com
}

\begin{abstract}
Database engineering (DBE) is one of the essential courses in computer science and engineering as database systems are widely used in every field. This course focuses on database design, data storage and retrieval in efficient manner. It is an observation that novice learners find database design more difficult. To make database design process easier and understandable, Project based learning popularly known as PBL is already proven to be successful active learning strategy. In PBL, students work on real time project through various stages increasing their knowledge and level of understanding. Here, our study reports blend of PBL with traditional teaching for DBE course for third year students in computer science and Engineering. Focus was not only to get acquainted with database concepts \&, enhance knowledge but also to successfully implement real world database application. Thus, the primary objective was to apply database concepts into practice and secondary objectives was to inculcate team work experience, communication skills, exposure to complexities of real word problem and find the solutions. We formed eighteen teams in all which worked on various real world problems through seven phases of PBL and at the end of semester, fourteen teams successfully implemented applications.
\end{abstract}

Keywords: Database Engineering, Project Based Learning, Real world problems, Database concepts

\section{INTRODUCTION}

Database engineering is one of the essential courses in computer science and engineering. This course deals with database design, data storage and retrieval in efficient manner. The database system gives abstract view of data at various levels. As various users interact with the database system, database designer needs to think how, where \& what data will be stored, which data structures will be used, whether to prefer simple or complex data structures. Developer needs to define schema and data model. Data model will define data, relationships, semantics and consistency constraints. Database designer needs to know data definition language (DDL) to define database schema and data manipulation language (DML) to access and manipulate data. Defining schema includes properties of data, domain constraints, integrity constraints, authorization etc. Once data model is finalized, that model needs to be converted into logical and physical database design. Thus, database design is one of very crucial step of database management system. To come up with good database design, designer shall understand user requirements thoroughly, and able to develop good data model. This deep knowledge about all database concepts can be obtained through real time project than simply doing small independent assignments in laboratory session using traditional method. Stephan Bell [1] says PBL is a studentdriven, teacher- facilitated approach to learning. PBL allows students to learn concept and apply in real time scenario. PBL maps theoretical knowledge to practical implementation which leads to up-gradation of skill sets while solving real world problems. In the changing era, Project-based learning (PBL) provides a facility to analyze real-world problems and demands. With this active and engaged learning, students get profound knowledge in the respective subject.

There is variation in number of steps followed in PBL but common steps involved are: Identification of problem statement, formation of teams, Requirement analysis and design, implementation or development, testing and deployment or project delivery.

Hence we have used PBL as an active learning strategy in teaching DBE course. Our approach focuses on real time project development following the various phases of PBL. PBL helped students not only to design \& create database, get clarity in database concepts but also to develop real time applications. PBL also inculcated skills required by industry.

\section{LITERATURE REVIEW}

Various researchers used various instructional strategies including PBL, project management tools to teach database design concepts. Julie E. Mills et.al.[2] discussed application of project based and problem based learning to engineering education and also discussed difference between them. Author discussed that engineer graduates lack design experience, communication skills and teamwork experience. To overcome these issues is to redesign curriculum but most institutions will prefer to shift their fundamental basis to 
problem or project based learning. Stephan Bell [1] says that PBL is an innovative approach to learning that teaches a multitude of strategies critical for success in the twenty-first century. It not only makes students advanced problem solvers but also good communicators. Thomas M Connolly [3] stated that fresh graduates as well few IT professionals are not able to handle complexities occurred during real time problems. He used principals in constructivist epistemology to teach database design $\&$ analysis concept to overcome this issue. Cesar Dominguez et.al.[4] integrated PBL, project management techniques $\&$ tools in technique called practical task development for teaching database design concepts.

L. Helle [5] revealed that the majority of researchers worked on project-based learning are focusing on the implementation of individual courses. Also there are several issues in PBL implementation. Claus Pahl et.al.[6] used multimedia system based on the virtual apprenticeship model to acquire knowledge and skills in database design. There are various challenges of PBL from student's and teacher's perspective. Students need to face problems such as identification of real world problem, time required to get solution to problem, surety of successful implementation of problem whereas teachers face the problem of equivalence of difficulty level of every problem statement, assessment of solution, assessment of contribution of each team member, their knowledge in that field etc.

We tried to blend PBL with traditional teaching for DBE course. The primary objective was to apply database concepts into practice and secondary objectives was to inculcate team work experience, communication skills, exposure to complexities of real word problem.

\section{IMPLEMENTATION DETAILS}

We have implemented PBL while teaching Database engineering course to third year students from computer science engineering. Structure includes four theory lectures and two hours lab session. Curriculum [7] includes Introduction to database, relational model, database design \& E-R model, Indexing, Normalization, Transaction and concurrency control.

Course outcomes (COs) of this course are:

At the end of the course a student will be able to

1. Demonstrate the basic concepts of relational data model, entity-relationship model, relational database design, relational algebra and SQL.

2. Design E-R diagrams to represent simple database for any real time application and formulate SQL queries on it.

3. Analyze a database design and improve the design by normalization.

4. Demonstrate knowledge of ACID properties of a transaction and several techniques of concurrency control.

In the first run of course, concepts were taught in classroom whereas short assignments were given lab session on various database topics as shown in Fig.1.

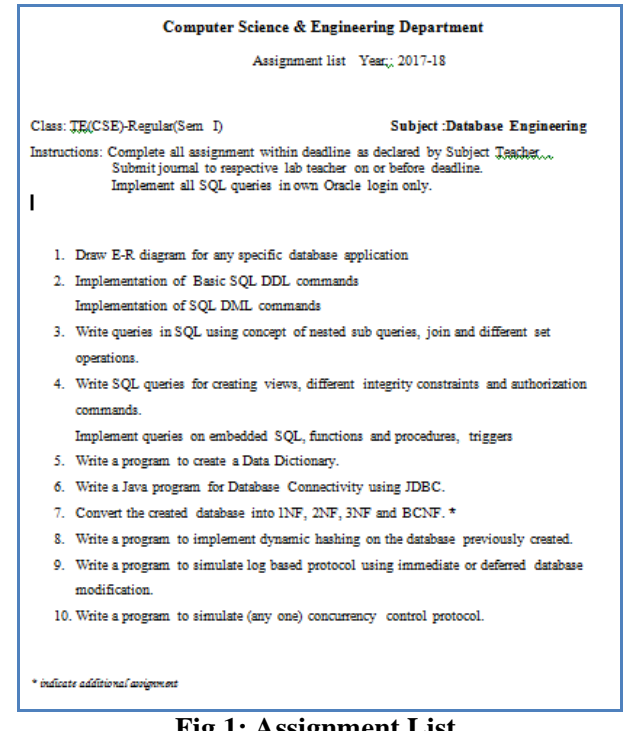

Fig 1: Assignment List

It was observed that students successfully completed above assignments on given or available database but they were not able to design database for real world problem which they selected in the final year under course-head of 'Project'. Therefore, we introduced PBL activity to third year students in DBE course with an objective of improving understanding of database concepts through PBL and achieve first three outcomes. This PBL activity was organised in seven stages.

Duration of activity was one semester. Assessment was carried out at each phase.

All database concepts were divided among various tasks such as topic selection, requirement analysis, database design, creation of database using any backend software, design of front end and connect front end to database through APIs and finally implementation of complete application. This activity started with team formation.

\section{A] Team formation}

At this phase, students were asked to form a team of four members of their choice. Each class is divided amongst four batches and in every batch four to five teams were formed. Each team comprises maximum four members. An objective of team formation was to enhance team management skills, communication skills through various interactions among students and teacher.

\section{B] Topic selection}

After team formation, one week time was given for topic selection. Students were given liberty to choose their project topics. With a wide scope of selection of topics, the areas ranged from Automotive, Banking, Education, Legal, Government, Pharmaceutical, Music, Sports etc. Teaching Faculty ensured that no two teams from the class have selected same topic. Table 1 shows team information and project titles finalised by them. 
Table 1: Team Formation

\begin{tabular}{|c|c|c|}
\hline \multicolumn{3}{|c|}{$\begin{array}{l}\text { Class : TECSE } \\
\text { Subject : Database Engineering } \\
\text { Project Based Learning }\end{array}$} \\
\hline Sr. No. & $\begin{array}{l}\text { Roll } \\
\text { No. }\end{array}$ & Project Name \\
\hline \multirow{3}{*}{ Group 1} & 1 & \multirow{3}{*}{ Travelling Services } \\
\hline & $\frac{5}{7}$ & \\
\hline & $\frac{7}{6}$ & \\
\hline \multirow{4}{*}{ Group 2} & 57 & \multirow{4}{*}{$\begin{array}{l}\text { Supermarket Billing } \\
\text { System }\end{array}$} \\
\hline & 81 & \\
\hline & 39 & \\
\hline & 49 & \\
\hline \multirow{4}{*}{ Group 3} & 42 & \multirow{4}{*}{ Online Shopping Model } \\
\hline & 46 & \\
\hline & 44 & \\
\hline & 48 & \\
\hline \multirow{4}{*}{ Group 4} & 41 & \multirow{4}{*}{ Pharma Billing System } \\
\hline & 47 & \\
\hline & 52 & \\
\hline & 54 & \\
\hline
\end{tabular}

C] Requirement analysis and Logical Design

Teams first collected requirements from users and analysed. Students identified the entities and their attributes, relationship amongst entities and cardinality mapping, key formation etc. They converted these requirements into conceptual design.

Concept of normalization is applied for removing redundancies, if any. Through iterative process, final schema is designed. This conceptual schema is converted into logical design using Entityrelation (E-R) diagram. Various tools such as EDraw, ERDPlus, LucidChart are used to draw the ER diagrams. Faculty member assessed these E-R diagrams before creation of the database. Following figure shows E-R diagram of Blood Bank application. Once E-R diagrams are assessed and approved, these diagrams are reduced to relational schemas. Thus, in this phase student demonstrated database design and E-R diagram. They also analysed their design and applied normalization concepts to come with good design.

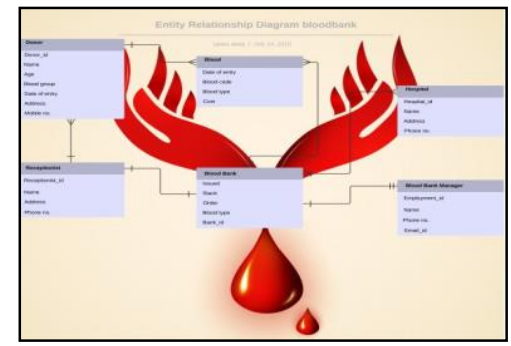

Fig 2: ER Diagram

D] Creation of database

Oracle is used as backend for creating database. Structured Query Language (SQL) is used for creating and manipulating database. DDL commands are used to create database and tables. Thus DDL part of SQL concept is applied at this stage. Once database is ready, next phase of development of front end started.

\section{E] Front end design}

To access data and manipulate data from database, front ends are designed for end users using Java or PHP. 80\% students used Java platform. Various forms are designed for various operations on data. Working of all menus, buttons and other controls is tested at this stage.

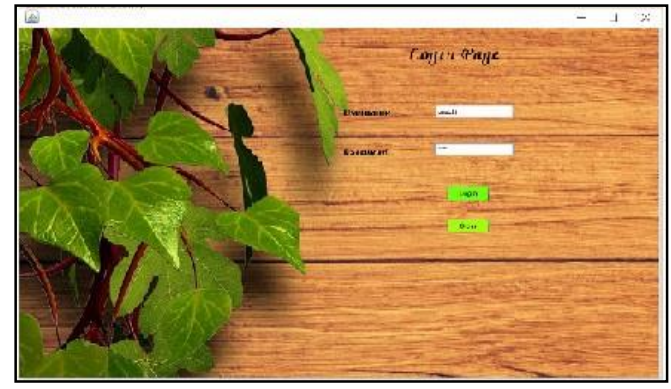

Fig 3: Front end application

F] Connecting Frontend with backend

Application Program Interface (API) such ODBC and JDBC are used to connect front end with database.

Students used DML commands such as insert, update, and delete to manipulate data demonstrating SQL concepts. Samples form is shown in Fig.4.

At this stage, students tested connectivity of controls with the fields, validations, integrity checks and ensured that data manipulations operations are working properly. Actions on each event are executing properly.

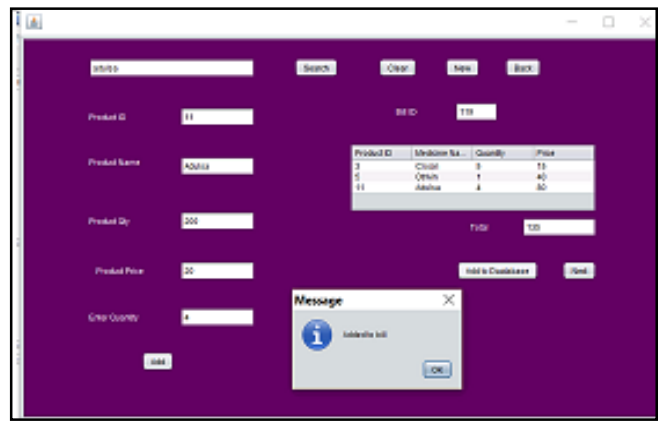

Fig. 4 : Screen accessing data

G] Project Presentation and Final Assessment:

At the end of semester, all teams presented their work in front of panel, second year students and end users. Here, Second year students got the idea of PBL and project. Rubrics were defined for assessment including parameters topic selection, database design, front end, functionality of complete project, presentation skills and team work. All out of eighteen teams, fourteen teams successfully completed the project whereas remaining 4 teams completed project partially. These four teams could design database successfully but they faced problem in developing complete project ready for deployment.

Thus, we observed that in previous run of DBE course, students could run DDL and DML commands successfully for a given schema but they could not come up with good schema for real world applications. In this run, students executed assignments indirectly through PBL and come up with good database design as well database application. At the end of semester, we conduct course exit survey on the scale of 1(lower) to 5 (larger) to calculate CO attainment. In DBE course exit survey, it was found that average attainment of first three outcomes was 4 whereas average attainment of fourth outcome was 3 . 


\section{CONCLUSION}

Here, we have presented a case study how PBL can be blended with traditional teaching to improve conceptual understanding of database concepts in DBE course. In laboratory sessions of DBE course, instead of carrying out independent assignments to demonstrate database concepts, these theoretical database concepts were mapped into real world problems using PBL leading to improvement in skillsets required in database design and application development by industry. In future, students will be encouraged to select more complex applications in PBL activity.

\section{REFERENCES}

[1] Stephan Bell, "Project-Based Learning for the 21st Century: Skills for the Future", Journal The Clearing House: A Journal of Educational Strategies, Issues and Ideas, Volume 83, 2010 - Issue 2,Pages 39-43

[2] Julie E. Mills, David F. Treagust "Engineering Education - Is Problembased Or Project-Based Learning The Answer?", Australasian Journal Of Engineering Education, ISSN 1324- 5821

[3] Thomas M Connolly , Carolyn E Begg, "A Constructivist- Based Approach to Teaching Database Analysis and Design", Journal of Information Systems Education, 2005, Pages 43-53

[4] Cesar Dominguaz \& Arturo Jaime, "A Project Based learning in Database Design learning", Journal Educational Psychologist Volume 20, 1985 - Issue 4, Pages 191-206,

Published online: 08 Jun 2010

[5] Helle L., P. Tynjala, and E. Olkinuora, "Project-based learning in post-secondary education - Theory, practice and rubber sling shots", 2006, Higher Education, Volume 51, Pages 287-314

[6] Claus Pahl , Ronan Barrett , Claire Kenny, "Supporting active database learning and training through interactive multimedia", Proceedings of the 9th annual SIGCSE conference on Innovation and technology in computer science education, June 28-30, 2004, Leeds, United Kingdom

[7] Abraham Silberschatz, Henry F. Korth, S. Sudarshan, "Database System Concepts", sixth edition, McGraw Hill Publications 